\title{
Shorting Plate Planar Inverted Folded Antenna on LC Substrate for Bluetooth Application
}

\author{
B.T.P. Madhav ${ }^{1, *}$, VGKM Pisipati ${ }^{1}$, Habibulla Khan ${ }^{1}$, P.V. Datta Prasad ${ }^{2}$ \\ ${ }^{1} L C R C-R \& D$, Department of ECE, $K$ L University, Guntur DT, AP, India \\ ${ }^{2}$ Head, Dpt of Physics, Hindu College, Machilipatnam, AP, India
}

Received 30 June 2012; Accepted 25 September 2012

\begin{abstract}
Number of investigations done to reduce the size of the microstrip patch antennas at a fixed operating frequency. In general microstrip antennas are half wavelength structures and are operated at the fundamental resonant mode TM01 or TM10. To reduce the size without disturbing the substrate material permittivity value we are having some special techniques like shorting pin, shorting plate, shorting wall and some other slot models. This paper describes the design and simulation of planar inverted folded antenna with shorting plate model on the liquid crystal substrate material. The present study includes verification of radiation patterns, return loss and field distributions. The operating frequency is chosen $2.4 \mathrm{GHz}$ for Bluetooth applications. All the output parameters are simulated using commercial Ansoft-HFSS Software.
\end{abstract}

Keywords: Shorting Plate, Planar Inverted Folded Antenna (PIFA), Liquid Crystal Substrate, Bluetooth.

\section{Introduction}

Planar Inverted folded antenna is one of the mostly used antenna in the mobile phones for various applications like, transmission and reception of signals, Bluetooth, Internet etc. The Inverted F Antenna (IFA) typically consists of a rectangular planar element located above a ground plane, a short circuiting plate or pin, and a feeding mechanism for the planar element. The Inverted F antenna is a variant of the monopole where the top section has been folded down so as to be parallel with the ground plane. This is done to reduce the height of the antenna, while maintaining a resonant trace length. This parallel section introduces capacitance to the input impedance of the antenna, which is compensated by implementing a short-circuit stub [1-3].

The ground plane of the antenna plays a significant role in its operation. Excitation of currents in the printed IFA causes excitation of currents in the ground plane. The resulting electromagnetic field is formed by the interaction of the IFA and an image of itself below the ground plane. Its behavior as a perfect energy reflector is consistent only when the ground plane is infinite or very much larger in its dimensions than the monopole itself. In practice the metallic layers are of comparable dimensions to the monopole and act as the other part of the dipole [4-6].

PIFA can be considered as a kind of linear Inverted $\mathrm{F}$ antenna (IFA) with the wire radiator element replaced by a plate to expand the bandwidth.

One advantage of PIFA is that can be hiding into the

*E-mail address: madhav.mtech@gmail.com

ISSN: 1791-2377 @ 2012Kavala Institute of Technology. All rights reserved. housing of the mobile when comparable to whip/rod/helix antennas.

Second advantage of PIFA is having reduced backward radiation toward the user's head, minimizing the electromagnetic wave power absorption (SAR) and enhances antenna performance.

Third advantage is that PIFA it exhibits moderate to high gain in both vertical and horizontal states of polarization. This feature is very useful in certain wireless communications where the antenna orientation is not fixed and the reflections are present from the different corners of the environment. In those cases, the important parameter to be considered is the total field that is the vector sum of horizontal and vertical states of polarization [7-9].

Narrow bandwidth characteristic of PIFA is one of the limitations for its commercial application for wireless mobile. The shorting post near the feed probe point of usual PIFA types is good method for reducing the antenna size, but this result into the narrow impedance bandwidth [10].

\section{Techniques to increase the Bandwidth for PIFA:}

Bandwidth is affected very much by the size of the ground plane. By varying the size of the ground plane, the bandwidth of a PIFA can be adjusted. For example, reducing the ground plane can effectively broaden the bandwidth of the antenna system. To reduce the quality factor of the structure (and to increase the bandwidth), can be inserted several slits at the ground plane edges. Use of thick air substrate to lower the Q and increase the bandwidth [11-13]. 
Using parasitic resonators with resonant lengths close to main resonant frequency. Adjusting the location and the spacing between two shorting posts. Excitation of multiple modes designed to be close together or far apart depending on requirements. Using stacked elements it will increase the Bandwidth [14-15].

\section{Antenna Dimensions}

The resonant frequency is $2.4 \mathrm{GHz}$ and patch dimension along $\mathrm{x}$-axis is $12 \mathrm{~mm}$, patch dimension along $\mathrm{y}$-axis is 14 $\mathrm{mm}$. Substrate material of liquid crystal is chosen in this present work and its relative permittivity is 2.55 and loss tangent is 0.03 . Substrate dimension along $\mathrm{x}$-axis is $42 \mathrm{~mm}$ and $\mathrm{y}$-axis is $65 \mathrm{~mm}$. feed location along $\mathrm{y}$-axis is $-16.5 \mathrm{~mm}$, coaxial inner radius of $1.6 \mathrm{~mm}$ and outer radius of $5.5 \mathrm{~mm}$ and feed length of $16.3 \mathrm{~mm}$. Fig. 1 shows the shorting plate PIF Antenna on LC Substrate.

\section{Results and Analysis}

The simulation results are giving good agreement for the applicability of the proposed antenna. The return loss for the proposed antenna is shown in Fig. 2. The return loss obtained at $2.4 \mathrm{GHz}$ is about $-38.10 \mathrm{~dB}$.

At some frequencies a given antenna will not be matched to the transmission line, and will not accept or radiate power, while at those frequencies where the antenna is designed to operate, the impedance of the antenna will allow the electromagnetic energy to pass into the structure and radiate into the surrounding space. These frequencies would be deemed to be inside the antenna's impedance bandwidth. Figure (3) shows the input impedance smith chart. the rms of 0.75 and impedance bandwidth of $0.85 \%$ is attained from the current design.

Fig. 4 shows the two dimensional gain curve for the antenna. Maximum gain of $3.91 \mathrm{~dB}$ can be attained from the current model and it shown in the Fig. 4.

The radiation of the antenna is expressed in terms of the field strength $\mathrm{E}$ (in $\mathrm{V} / \mathrm{m}$ ), and then the graphical representation is called field strength pattern or field radiation pattern. Similarly if the radiation of the antenna is expressed in terms of the power per unit solid angle, then the graphical representation is called power radiation pattern. Fig. 5, 6, 7 and 8 shows the radiation pattern of the antenna. The far-zone electric field lies in the E-plane and far-zone magnetic field lies in the H-plane. The patterns in these planes are referred to as the $\mathrm{E}$ and $\mathrm{H}$ plane patterns respectively. Fig. 5 and 6 shows the radiation pattern of Eplane(y-z plane) in Polar coordinates and 3-Dimensional view. Fig. 7 and 8 shows the radiation pattern of H-plane (xz plane) in Polar coordinates and 3-Dimensional view.

The axial ratio is a parameter which measures the purity of the circularly polarized wave. The axial ratio will be larger than unity when the frequency deviates from f0. Figure (9) shows the axial ratio for the current model in 3-Dimensional view.

Fig. 10 shows the VSWR Vs frequency curve and it is showing the VSWR of 1.02 at desired frequency. The current result maintains the 2:1 ratio of VSWR as per the standards. These results showing the applicability of this antenna for the proposed operation.

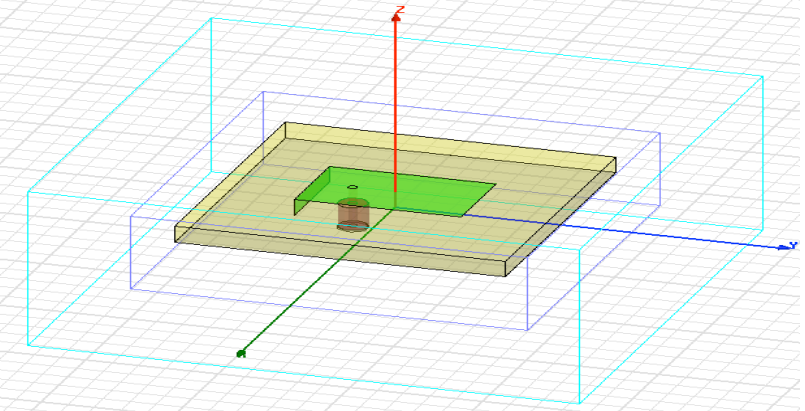

Fig. 1. Shorting Plate PIF Antenna.

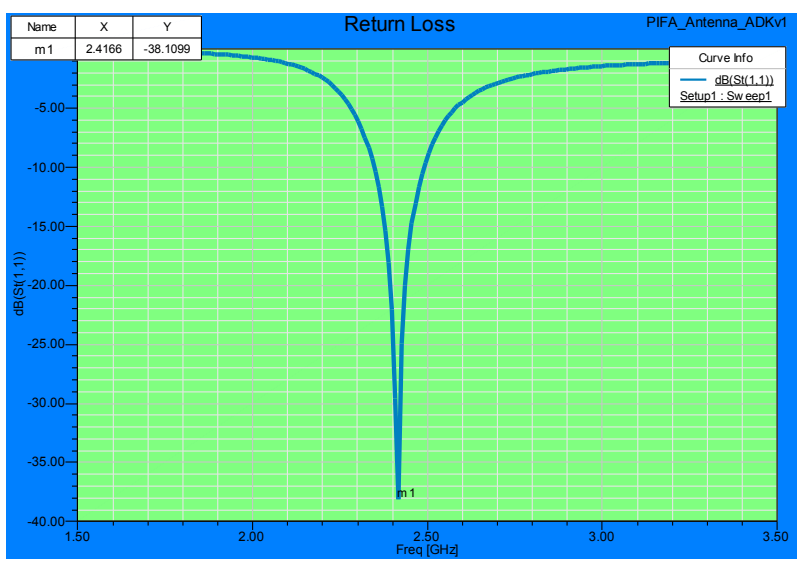

Fig. 2. Return loss Vs Frequency.

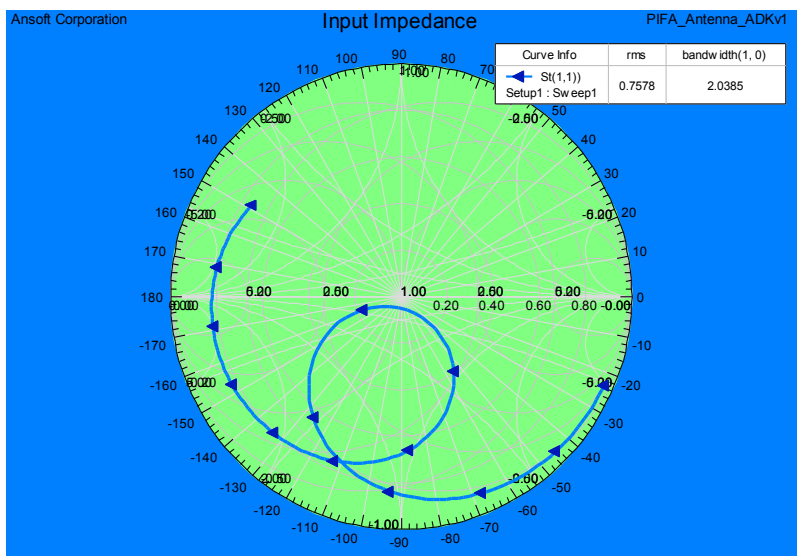

Fig. 3. Input Impedance smith chart.

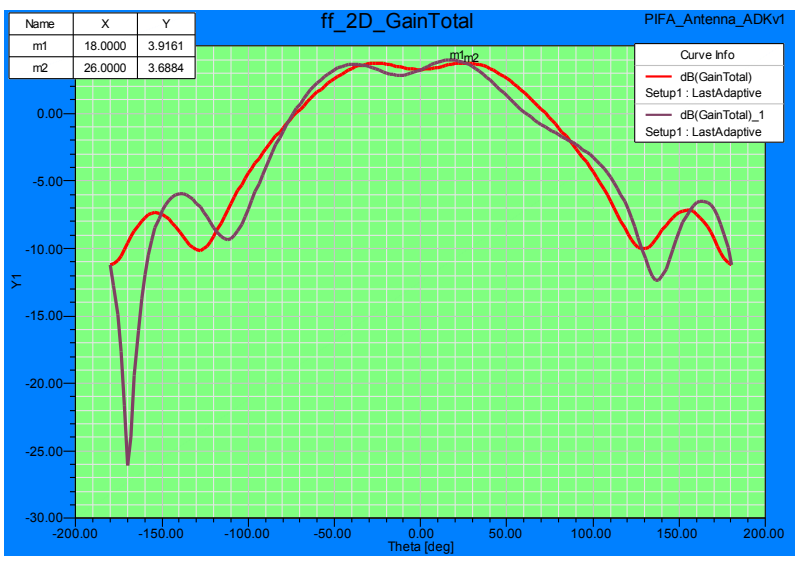

Fig. 4. Two Dimensional Gain. 


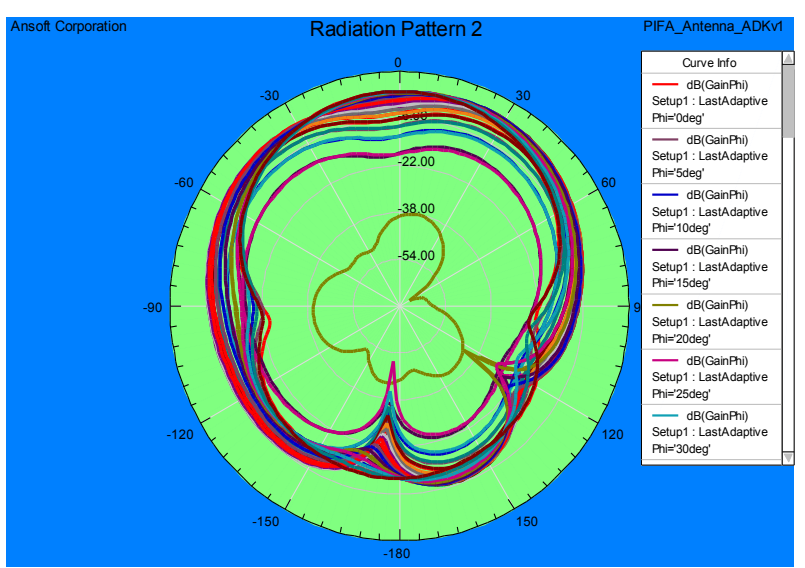

Fig. 5. Polar Plot for radiation pattern in phi direction.
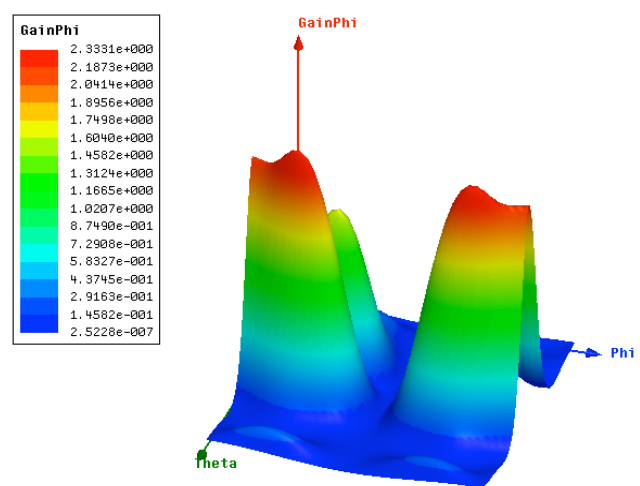

Fig. 6. 3D-Radiation Pattern in Phi direction.

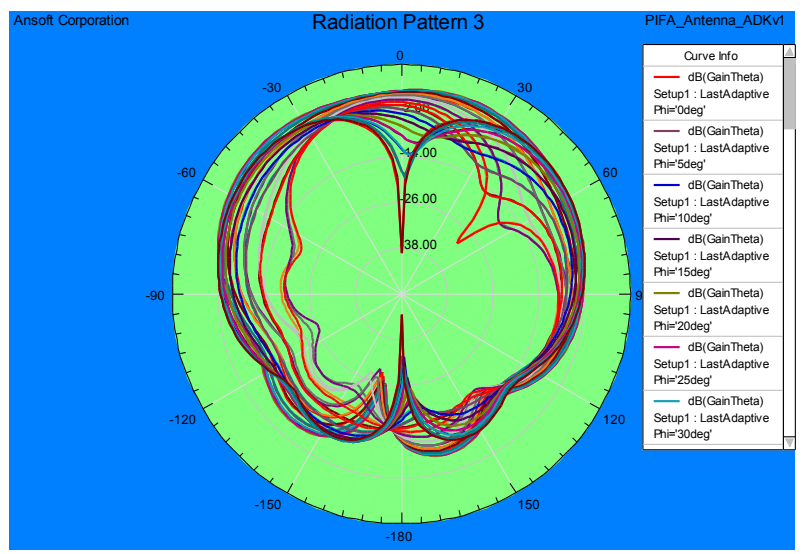

Fig. 7. Polar Plot for radiation pattern in theta direction.

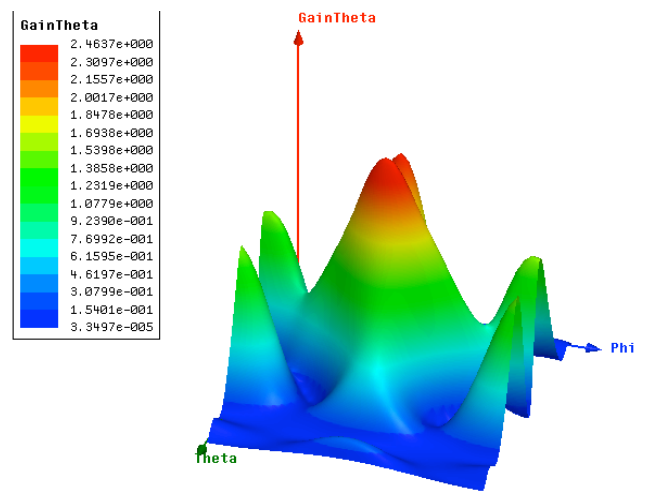

Fig. 8. 3D-Radiation Pattern in Theta direction.
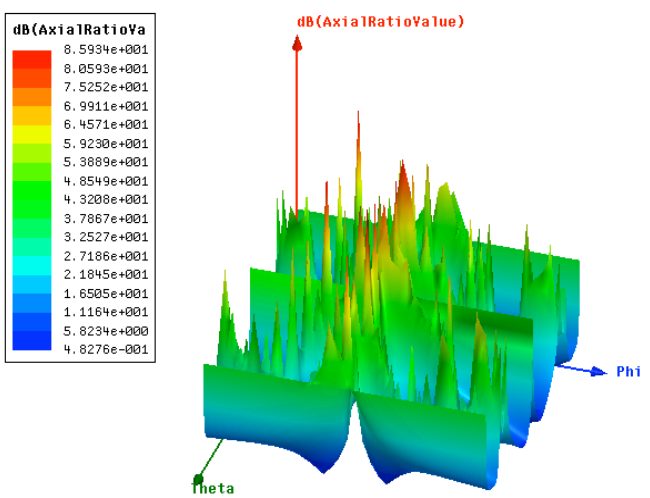

Fig. 9. 3D-Axial Ratio.

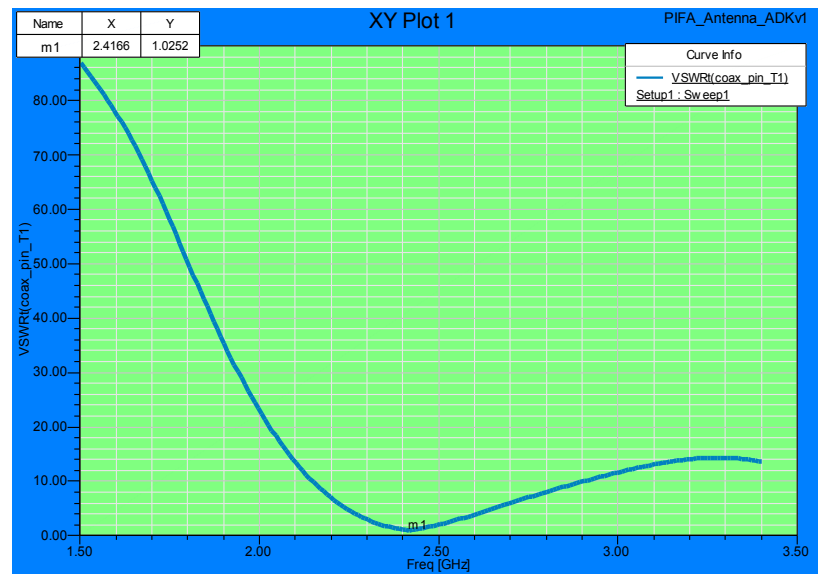

Fig. 10. VSWR Vs Frequency.

\section{Conclusion}

The Simulational investigations showing good results for the applicability of this proposed antenna at microwave frequencies. The results are in very good agreement with the industry and standard published antenna requirements with respect to ease of fabrication, compactness and volume miniaturization compared to other antennas so far designed for similar applications. Input impedance bandwidth of $0.85 \%$ enhancement can be achieved from the current antenna. The results are showing the applicability of the Liquid crystal based antennas in various applications of the communication systems.

Acknowledgments: The authors B.T.P. Madhav, Prof. VGKM Pisipati express their thanks to the management of $\mathrm{K}$ L University and Department of Electronics and Communication Engineering for their support. Further, VGKM Pisipati acknowledges the financial support of Department of Science and Technology through the grant No.SR/S2/CMP-0071/2008.

\section{References}


1. Boyle, K.R., Steeneken, P.G., "A Five-Band Reconfigurable PIFA for Mobile Phones", Antennas and Propagation, IEEE Transactions, Vol.55, 3300 - 3309, Nov. 2007.

2. B.T.P.Madhav, Prof. VGKM Pisipati, N.V.K Ramesh, Prof Habibulla Khan, Prof. P.V.Datta Prasad, "PLANAR INVERTEDF ANTENNA ON LIQUID CRYSTAL POLYMER SUBSTRATE FOR PCS, UMTS, WIBRO APPLICATIONS", APPN Journal of Engineering and Applied Sciences, VOL. 6, NO. 4, APRIL 2011 ISSN 1819-6608.

3. K.Praveen Kumar, N.Srinivas Sri Chaitanya, P.Rakesh Kumar, B.T.P.Madhav, N.V.K.Ramesh, B.Nagaraju Nayak, Comparative Analysis of Shorting Pin and Shorting Plate Models for Size Reduction in the Microstrip Patch Antennas, International Journal of Communication Engineering Applications-IJCEA, http://technicaljournals.org ISSN: 2230-8504; e-ISSN-22308512 Vol 02, Issue 04; July 2011

4. Belhadef, Y., Hacene, N.B., "PIFAS antennas design for mobile communications", Systems, Signal Processing and their Applications (WOSSPA), 2011 7th International Workshop, 119122, May. 2011.

5. Byung Chan Kim, Je Hoon Yun, Hyung Do Choi, "Small wideband PIFA for mobile phones at $1800 \mathrm{MHz}$ ", Vehicular Technology Conference, 2004. VTC 2004-Spring. 2004 IEEE 59th, Vol.1, 27-29, May 2004

6. Diallo, A.; Luxey, C.; Le Thuc, P.; Staraj, R.; Kossiavas, G.; "Reduction of the mutual coupling between two planar inverted-F antennas working in close radiocommunication standards", Applied Electromagnetics and Communications, 2005. ICECom 2005. 18th International Conference, 1-4, 12-14 Oct. 2005.
7. Komulainen, M.; Berg, M.; Jantunen, H.; Salonen, E.T.; Free, C.; "A Frequency Tuning Method for a Planar Inverted-F Antenna", Antennas and Propagation, IEEE Transactions, Vol.56, 944 - 950, April 2008.

8. Komulainen, Mikko; Berg, Markus; Mahonen, Juho; Jantunen, Heli; Salonen, Erkki; "Frequency reconfigurable planar inverted-F antennas for portable wireless devices", Antennas and Propagation, 2006. EuCAP 2006. First European Conference, 1-6, 6-10 Nov. 2006.

9. Razali, A.R.; Bialkowski, M.E.; Tsai, F.-C.E.; "Multi-band planar inverted-F antenna with microstripline coupling to open-end ground slots", Microwave Conference, 2009. APMC 2009. Asia Pacific, 2471 - 2474, 7-10 Dec. 2009.

10. Michael, K.; Kucharski, A.A.; "Optimization of Multiple-Short PIFA for Broadband Communication", EUROCON, 2007. The International Conference on \&\#34, 61-64, 9-12 Sept. 2007.

11. Kin-Lu Wong, "Compact and Broadband Microstrip Antennas", Copyright 2002 John Wiley \& Sons, Inc.

12. Sang il Kwak; Dong-Uk Sim; Jong Hwa Kwon; "Design of Optimized Multilayer PIFA with the EBG Structure for SAR Reduction in Mobile Applications", Electromagnetic Compatibility, IEEE Transactions, Vol.53, 325-331, May-2011.

13. David M Pozar, Microwave and RF design of wireless systems, John Wiley and sons, 3rd edition, 2004.

14. K. H. Chan, K. M. Chow, L. C. Fung and S. W. Leong, "SAR of internal antenna in mobile phone applications", Microwave and Optical Tech. Letters, vol. 4, pp. 286-290, May 2005.

15. M. Jayewardene, P. McEvoy, J. C. Vardaxoglou, O. A. Saraereh, "Quad-band handset antenna for GSM900/ DCS1800/ PCS1900/UMTS bands”, Proceedings IEEE IWAT, 2006. 